\title{
Promoting innovative undergraduate education project with interdisciplinary integration
}

\author{
Rui Xiong \\ Qiming School \\ Huazhong University of Science and Technology \\ Wuhan, China \\ x_ruihg@ hust.edu.cn
}

\author{
Li Zhu \\ School of Humanities \\ College of International Business and Economics, WTU \\ Wuhan, China \\ julie0233@qq.com
}

\begin{abstract}
The innovative education system is constructed collaboratively with a "broad engineering disciplines" coalition, with the ability-directed cultivation objectives of engineering talents. The pilot project is established within the cultivation program, building interdisciplinary teaching teams, courses, practice sessions and practice bases, and also launching teaching reforms and practices accordingly.
\end{abstract}

Keywords - innovative education; interdisciplinary integration; talent cultivation; mechanism construction.

\section{INTRODUCTION}

There are several challenges of engineering education, including promoting the interdisciplinary and trans-disciplinary integration, constructing "new engineering," and make "the cultivated students have the desire and ability to lead, imagine and create the needs of future society, while focusing on real demands of engineering at the same time" [1].

The well-known and high-level universities at home and abroad have paid growing attention to the interdisciplinary pattern of course organization with its focus on problems. Each discipline has a role to play and interconnects with each other in the process of problem-solving [2] [3]. For instance, most courses of MIT's interdisciplinary education focus on social problems, life experience, human phenomenon, adopting the research method of scientific experimental research. The courses emphasize both the impartation and transfer of knowledge, and also the integration and interrelation of disciplines. Their course designs would rather sacrifice the discipline depth guarantee, in order to guarantee the fundamentality of disciplinary knowledge and flexibility of problem-solving. It is believed that the best students are those who have firm foundation, are good at cooperation with others, learning new things, and developing new abilities, rather than those who have accurate and deep knowledge of a certain area.

To explore the way of talent cultivation in undergraduate education, China has widely adopted such pilot projects as those which are based on the Excellent Human Resource Cultivation scheme. Since there has been no cultivation system and top level design of innovative talents, there is a serious shortage of cultivation for interdisciplinary in novative education and collaboration abilities, which would enable students to have the vision, ability and systematic knowledge of facing future problems. "Innovative education achievements" are mostly confined to college students' extra-curriculum activities of scientific and technological innovation, which are oriented inaccurately and the effects are difficult to evaluate, with the radiating demonstration effect fails to be demonstrated to students.

The author is now working in the team of the Qiming School at the Huazhong University of Science and Technology. In the practice of undergraduate education, the team has investigated the building of innovative education system with the focus on interdisciplinary integration, constructing an educational platform of interdisciplinary integration and collaboration, launching teaching reforms that pay attention to humanity, ability and vision, and implementing related pilot projects, of which the achievements the team has made replicable design.

\section{THE CULTIVATION ORIENTATION OF INTERDISCIPLINARY INTEGRATION}

Higher engineering education should cultivate talents for future society. None of modern and future projects, or social problems, can be solved by any single discipline, as there is no model answer to them. Students are able to face different problems after graduation only if universities provide education that is based on ability, problem-solving and free answers.

Currently, higher engineering education In China is still "discipline education" that is sort of narrow and still remains teaching single disciplines and knowledge points (teaching reforms still focus on the addition or reduction of one or two knowledge points or their practices). There is no radical change at all to talent cultivation.

There have also been many misunderstandings of innovative education for recent years. Innovative activities are restricted to extra-curriculum discipline contests or other extra-curriculum programs, in which only a few students are involved. The in-class 
education still emphasizes "teaching" more than "learning," and "learning" more than "practicing," lacking the design of innovative education, resulting in a situation in which innovative activities of science and technology are dominated by extracurriculum discipline contests.

For many years, teaching reforms of innovative talent cultivation implemented by universities have just been made credits of cultivation program swollen tremendously, by simply doing addition, while the difficultly of courses' knowledge points has increased. Therefore, the more reforms there are, the more internal credit hours there will be, and the heavier of the students' pressure is. Students may have lost the space and motivation of autonomous learning and research, and the so-called difficulty is still the duck-stuffing infusing behavior of knowledge points. Students' internal motivation of learning cannot be activated to give them innovative thought. This is the problem that besets the issue of innovative talent cultivation.

Since 2003, we have been launching the interdisciplinary education project within the cultivation program. The objectives and the design of talent cultivation are as follows:

- Not breaking away from the specialty (the specialty cultivation standard remains unchanged);

Implementing special interdisciplinary courses and practices with the combination of relevant disciplines.

- The cultivation of both thought and ability;

Starting with the quality and ability building of "innovative talents", and the orientation of cultivation objectives, redesigning necessary courses and sessions, fundamentally reforming teaching methods and evaluation system in fields such as basic courses, general courses, specialty courses and practice sessions.

According to the cultivation of engineering disciplinary thinking and ability, setting up cultivation system from cognition to product design that concerns society, establishing interdisciplinary courses progressively and incessantly that reflect the latest academic achievements, designing the innovation education and entrepreneurship system that are multi-disciplinary and multilayer.

Implementing large amount of investigative learning and active practice in class (the teaching reforms emphasize researchbased teaching models, and high-level teaching content that worth challenging), and practice of Flipped Classroom.

- Implementing collaborative talent cultivation between the college and enterprises to foster leading personnel for the future industries.

With the vision of cultivating eminent men of talent for the future, implementing the practice model that focuses on enterprise issues and problem-solving, organizing student teams of multi-disciplinary practice and launching research projects combining practical engineering problems, letting students be close to engineering and society, heading for enterprises and also letting enterprises pay attention to talent cultivation.

\section{Design of InNOVATIVE Education System AND THE Work That HAS BeEn Done}

Base on the educational idea that "innovative education [4] will not be restricted to elite students, but will try to exploit the potentials of all students as far as possible," we combined the cultivation program with innovative education of interdisciplinary integration, covered all students in pilot projects, and implemented the teaching design of different aspects, such as in and out of class, all layers of disciplines and the replicability.

\section{A. Setting up an interdisciplinary platform}

\section{a) Constructing interdisciplinary engineering education coalition, the "multi-discipline joint experimental class"}

Based on different engineering categories, adopting the pilot project method by promoting work in all areas by drawing upon the experience gained on key points, and constructing interdisciplinary engineering education coalition - the "multi-discipline united experimental class" constituted by "outstanding engineering program experimental class" of four specialties, that is, Machinery, Photo-electricity, Civil Engineering and Bio-medicine (Fig.1).

In the construction of new coalition, the final quality and ability guidance of talent cultivation is oriented by cultivation objectives, to reconstruct the cultivation program and cultivation process (sessions), launching the cultivation program design, courses integration, innovative models of course learning, so as to promote students' individualized development and competence of specialty, collaboration, and innovation. 




Fig.1 Multidisciplinary engineering education organization - "Multidisciplinary Joint Exp. Class"

\section{b) Program objectives}

The program is aimed to implement basic learning that is wide-caliber and enhances ability, and interdisciplinary course taking, as well as professional learning combined with practice. It is also aimed to strengthen the international vision and future-oriented abilities (such as the vision and collaboration), with a focus on responsibility education. Meanwhile, it plans to launch reforms of curriculum content and models. The program highlights ability orientation, interdisciplinary integration, and producing sensible, responsible, and capable talents, for the industry and future society.

The program design and implementation include:

- Constructing the ability-oriented cultivation program and curriculum systems, and implementing interdisciplinary the cultivation program (including reforms in the model of talent cultivation, the general education course system and its content, the specialty course system and its content, and the practicum teaching model)

- Reforming teachers' teaching models, and realizing teaching methods that promote students' autonomous learning

- Building the ability-based assessment system

- Establishing interdisciplinary practice base

c) Cultivation program reconstruction

Interdisciplinary integration should be discipline-based, launch joint practice and collaborative innovation. Innovative education should be included in the undergraduate talent cultivation program, with the emphasis on vision and collaboration, and in accordance with the program objectives and ability requirements.

The scheme makes "addition" (the courses added are all interdisciplinary courses), "zero addition" (to reform core courses, or establish interdisciplinary joint practice, perceiving one or more problems collectively, and conducting project-based and problem-solving practice collectively), and "subtraction" (the course integration), in order to stop credit expansion.

\section{d) Interdisciplinary curriculum design}

The program sets up approximately 20 special interdisciplinary courses of various subjects that are led and instructed by famous scholars. It also introduces several international online courses and international exchange programs, such as:

- A Top-level design course of engineering education "An Introduction to Engineering": a general education course aimed at developing students' macro thinking ability in engineering.

The teaching content focuses on guiding students to be concerned about serious issues of human and society, to be aware of the technology evolution and invention from a historical perspective, and to understand challenges towards engineering talents from a vision of the future; attaching importance to multidisciplinary connections in engineering (from basic and broad engineering perspectives), and to engineering attainments (including humanistic feelings); pay ing attention to engineering ethics, developing interest in engineering, and preliminary understanding of engineering collaboration. 
The teaching of methods focus on teaching basic thinking methods, and cultivating students through course teaching and course project sessions: making students understand history, current situations, and development trends of engineering technology; correctly understanding how engineering technological progress influence the objective world and society; developing preliminarily abilities of teamwork, and of acquiring and reviewing important literature.

- Freshman Seminar "Scientific Thinking and Methods": adopting the model of Flipped Classroom; learning and developing common thinking methods of scientific research by investigating, discussing, and combining important scientific and engineering progress and advanced subjects.

- "Design Thinking of Engineering Innovation" (optional) and "Social Design and Innovation Practice": include innovative design courses that are based on joint effort of trans-disciplinary labs, enterprises and foreign universities. The courses are aimed at guiding students to pay attention to society, underprivileged groups, environment, and development, and to develop methods of question-raising and problem-solving. The courses also emphasize multisource and integration of subjects to their learners, adopting the teaching model that combines lectures, multidisciplinary team design practice, and live seminars. These lead students to deeply understand and grasp social design, and the thinking model of engineering design, and to develop trans-disciplinary cooperation.

- Courses of innovative foundation and abilities: include AAFIE's online courses "International Engineering Foundations", "Findings, Invention, Creation, Innovation and Entrepreneurship", the summer program at the University of Manchester "New Product Development", Maker Space's "Realizing Ideas and Dreams" (digitalize and personalized design), "studies on installation of 3D Printers (multidisciplinary joint cognitive internship) ", etc.

- Courses of entrepreneurship education and other new technologies

\section{e) Internship and practice reforms}

In the view of cultivating excellent future talents, the program concerns and implements the multidisciplinary joint internship and practice model for solving problems in enterprises. Student teams of multidisciplinary practice launch research and development projects, based on practical engineering problems in enterprises, so that students can be closer to projects, society, and enterprises, and let enterprises pay more attention to talent cultivation.

\section{B. Implementing the teaching model of multidisciplinary integration}

In multidisciplinary integration teaching practice, the teaching model that multidisciplinary students are mixed and divided into different groups is adopted, as the meanings of this model go as follows:

- The model makes students from different specialties, in such an atmosphere, learn scientific thinking models and seek research methods; through research-based learning that is organized and guided, students realize that they can acquire knowledge and develop abilities by themselves, and all engineering or social problems cannot be solved by a single discipline; designing interdisciplinary collaboration platforms is necessary for students from different specialties.

- The model is not for multidisciplinary students to learn as many different disciplines as possible, but allows them to learn collectively, communicate and collaborate, and to receive education in multidisciplinary background from multiple scholars at the undergraduate stage. In learning experiences and teamwork under multidisciplinary integration, students enjoy multidisciplinary educational resources and share their own ideas in collaboration. Therefore, one student can get resources and ideas of multiple disciplines. (This is a sort of "living" integration.)

- The model helps students develop good ways of learning, such as acquiring knowledge from friends, classmates and colleagues, and storing the knowledge in friends. (This is because it involves broad and complex multidisciplinary knowledge. one cannot know all details about the knowledge, but he or she can know some knowledge points of other disciplines, with details stored in friends from these disciplines. - This is the educational method of Connetivism.)

- With multi-scholar interdisciplinary participation in interdisciplinary teaching teams, students can enjoy a larger number of disciplinary resources. Through offline face-to-face "warm" communication with famous teachers and scholars, students can gain some integrated development of emotion, personality, and wisdom.

\section{CONCLUSION}

It is replicable to construct innovation education system, based on the collaborative innovation model of "broad engineering" coalition, and to launch pilot projects of interdisciplinary innovative education within the cultivation program. When undergraduate students entered the university, they have received interdisciplinary education, and continued learning and doing research through interdisciplinary integration that emphasizes problem-solving, during their four-year study. The program has been successful, as the students have received multiple innovative prizes, with attention and approval from domestic and foreign media, peers colleagues, and the industry. 


\section{REFERENCES}

[1] P.G. Li, "How can engineering disciplines be new?", Higher Engineering Education Research, 2017. (In Chinese)

[2] H.L. Lei and Q. Gao, "Conceptual foundations, supporting conditions and major approaches of MIT interdisciplinary cultivation of undergraduates", China Higher Education, vol. 11, pp. 76-79, 2016, Information on Http://mp.weixin.qq.com/s/Ot99NXqtHfav5664aV--Cw (In Chinese)

[3] X. Luo, "Promoting comprehensive university development with interdisciplinary integration — a case study of Canadian universities", World Education Information, vol. 22, pp. 50-54, 2016.

Information on http://www.51science.cn/EKTodayArticle.aspx?articleD=8306 (In Chinese)

[4] P.G. Li, Knowing Universities, Beijing: The Commercial Press, 2015. (In Chinese) 